\title{
Correction to: Noise Characterization of InAs Based Composite Channel DG -MOSHEMT with Different Gate Dielectrics
}

\author{
G. Sujatha ${ }^{1}$ - N. Mohankumar ${ }^{2} \cdot$ R. Poornachandran ${ }^{3} \cdot$ R. Saravana Kumar ${ }^{4} \cdot$ Girish Shankar Mishra $^{2} \cdot$ V. Mahesh ${ }^{2}$. \\ M. Arunkumar ${ }^{2}$
}

Published online: 14 March 2021

(C) Springer Nature B.V. 2021

\section{Correction to: Silicon} https://doi.org/10.1007/s12633-021-00954-3

The original version of the article unfortunately contained an error.

The affiliation of the corresponding author is quoted wrong. The correction should be:

G. Sujatha - Anna University, Chennai, Tamil Nadu, India

The affiliation of the third author should be:

R. Poornachandran - ECE, V.S.B Engineering College, KARUR, Tamil Nadu, India

Publisher's Note Springer Nature remains neutral with regard to jurisdictional claims in published maps and institutional affiliations.

The online version of the original article can be found at https://doi.org/ 10.1007/s12633-021-00954-3

G. Sujatha

suji7jes@gmail.com

N. Mohankumar

mnagaraj2@gitam.edu

R. Poornachandran

poornachandran6493@gmail.com

R. Saravana Kumar

saravanaelectron@gmail.com

Girish Shankar Mishra

gmishra@gitam.edu
V. Mahesh

mvarier@gitam.edu

M. Arunkumar

amanohar@gitam.edu

Anna University, Chennai, Tamil Nadu, India

2 EECE, GITAM University, Bengaluru Campus, Bengaluru, Karnataka, India

3 ECE, V.S.B Engineering College, Karur, Tamil Nadu, India

4 ECE, Bannari Amman Institute of Technology, Anna University, Chennai, Tamil Nadu, India 